\title{
Reply to 15-00495
}

PM Hopkins, MB BS, MD, FRCA ${ }^{1}$, D Fiszer, PhD ${ }^{1}$, M-A Shaw, PhD ${ }^{1}$, and D. Roiz de Sa, MB BS, MSc, MCEM, FFSEM(UK) ${ }^{2}$

${ }^{1}$ Leeds Institute of Biomedical \& Clinical Sciences, School of Medicine, University of Leeds, UK

${ }^{2}$ Environmental Medicine and Science Division, Institute of Naval Medicine, Alverstoke, Hampshire, UK

\section{Authors' reply}

We would like to thank Dr Sagui for his kind words about our research and his interesting observations. The title and last sentence of his article are somewhat cryptic but we presume he is alluding to the well-known phenomenon whereby many individuals who develop exertional heat illness (EHI) do so through conscious maintenance of motor activity despite multiple adverse afferent inputs signalling failing physiological regulation. This may explain why many EHI cases occur during high stakes military exercises. Although interesting and important, this phenomenon is tangential to the focus of the work presented in our paper ${ }^{1}$. In attempting to draw attention to the volitional element of EHI, Dr Sagui seems to feel the need to dispute the premise that a subset of EHI cases occur in individuals with an inherited defect in skeletal muscle handling of calcium. The limited space permitted here prevents us from detailing the many flaws in his arguments but we would suggest he carefully re-reads our article and previous publications on this subject ${ }^{2,3}$. He might find it interesting to also read studies of transgenic murine models where disorders of skeletal muscle excitationcontraction coupling lead to heat intolerance ${ }^{4,5}$.

Perhaps Dr Sagui is finding it difficult to reconcile findings in exertional heatstroke in French military personnel with other literature. He implies that our EHI cohort may simply be a sample of the general population. We use the term exertional heat illness rather than exertional heatstroke as diagnosis of exertional heatstroke is often not established because of difficulty in measuring core body temperature in the field before cooling measures are implemented. It also recognises that patients with heat illness who do not meet the definition of heatstroke may still have a life-threatening condition. So while EHI may encompass a wide range of clinical presentations, the patients in our cohort all required hospital admission and invariably sustained tissue damage from their heat illness. The great majority were isolated casualties from group participation events in whom predisposing factors (concurrent illness, drugs, alcohol ingestion, etc.) had been excluded. Furthermore, they were all phenotypically characterised on at least two occasions as having impaired heat

Corresponding Author: Professor Philip M. Hopkins, M.D., F.R.C.A. St. James's University Hospital Malignant Hyperthermia Investigation Unit Leeds, LS9 7TF UNITED KINGDOM 44-113-206-5269 or 5274 FAX: 44-113-206 4140 p.m.hopkins@ leeds.ac.uk. Declaration of interests: Dr Hopkins is the Chairman of the European Malignant Hyperthermia Group. Dr Hopkins has not received any payments in connection with this role. 
tolerance in a standardised heat tolerance test. We therefore reject the suggestion that our EHI cohort was a sample from the general population. In the study cited by Sagui on French military personnel ${ }^{6}$, details of the criteria for inclusion in investigations were not given. We also have to point out that the in vitro contracture tests conducted in Marseille are not done according to the guidelines of the European $\mathrm{MH}$ group. We do not agree with the presumption that the severity of exertional heatstroke necessarily reflects the etiology: in our experience severity of EHI reflects the delay in making the diagnosis and implementing effective treatment, just as is the case with MH. Similarly, risk of recurrence of exertional heatstroke may not distinguish those genetically predisposed because a severe heat injury results in a prolonged period of heat intolerance that can take up to 2 years to resolve. Furthermore, as we point out in our paper ${ }^{1}$, the IVCT may not be fully sensitive for all types of genetic predisposition to EHI.

Finally, we have to correct Dr Sagui in his interpretation of our genetic findings. We did not conclude that polymorphisms were of "uncertain significance", as by definition polymorphisms are unlikely to be major genetic contributors to uncommon heritable traits. Of greater difficulty is the interpretation of rare variants in RYR1 and CACNA1S, as such variants have been found in more than $6 \%$ of control populations ${ }^{7}$. It is, therefore, inappropriate to make inferences based on the crude incidence of all variants in these genes in different subsets of our cohorts. Interpretation requires some assessment of likely functional significance. We have provided data on the prevalence of variants and their predicted pathogenicity but highlighted the limitations in this approach. We will seek to functionally characterise variants of interest but also extend our search for genetic variants implicated in MH and EHI. We wish Dr Sagui well in pursuit of his research into the role of brain function in the development of heatstroke.

\section{References}

1. Fiszer D, Shaw MA, Fisher NA, Carr IM, Gupta PK, Watkins EJ, Roiz de Sa D, Kim JH, Hopkins PM. Next generation sequencing of RYR1 and CACNA1S in malignant hyperthermia and exertional heat illness. Anesthesiology. 2015; 122:1033-46. [PubMed: 25658027]

2. Hopkins PM, Ellis FR, Halsall PJ. Evidence for related myopathies in exertional heat stroke and malignant hyperthermia. Lancet. 1991; 338:1491-2. [PubMed: 1683922]

3. Hopkins PM. Is there a link between malignant hyperthermia and exertional heat illness? Br J Sports Med. 2007; 41:283-4. [PubMed: 17261558]

4. Durham WJ, Aracena-Parks P, Long C, Rossi AE, Goonasekera SA, Boncompagni S, Galvan DL, Gilman CP, Baker MR, Shirokova N, Protasi F, Dirksen R, Hamilton SL. RyR1 S-nitrosylation underlies environmental heat stroke and sudden death in Y522S RyR1 knock-in mice. Cell. 2008; 133:53-65. [PubMed: 18394989]

5. Dainese M, Quarta M, Lyfenko AD, Paolini C, Canato M, Reggiani C, Dirksen RT, Protasi F. Anesthetic- and heat-induced sudden death in calsequestrin-1-knockout mice. FASEB J. 2009; 23:1710-20. [PubMed: 19237502]

6. Sagui E, Montigon C, Abriat A, Jouvion A, Duron-Martinaud S, Canini F, Zagnoli F, Bendahan D, Figarella-Branger D, Bregigeon M, Brosset C. Is there a link between exertional heat stroke and susceptibility to malignant hyperthermia? PLoS One. 2015; 10:e0135496. [PubMed: 26258863]

7. Kim J, Jarvik GP, Browning BL, Rajagopalan R, Gordon AS, Rieder MJ, Robertson PD, Nickerson DA, Fisher NA, Hopkins PM. Exome sequencing reveals novel rare variants in ryanodine receptor and calcium channel genes in malignant hyperthermia families. Anesthesiology. 2013; 119:105465. [PubMed: 24013571] 